

\title{
Experimental study of the viscoelastic properties of green poplar wood during maturation
}

\author{
Guillaume G. Pot, Emmanuel E. Toussaint, Catherine C. Coutand,
}

Jean-Benoit J.-B. Le Cam

\section{To cite this version:}

Guillaume G. Pot, Emmanuel E. Toussaint, Catherine C. Coutand, Jean-Benoit J.-B. Le Cam. Experimental study of the viscoelastic properties of green poplar wood during maturation. Journal of Materials Science, 2013, 48 (17), pp.6065 - 6073. 10.1007/s10853-013-7403-9 . hal-00964823

\section{HAL Id: hal-00964823 \\ https://hal.science/hal-00964823}

Submitted on 1 Jun 2020

HAL is a multi-disciplinary open access archive for the deposit and dissemination of scientific research documents, whether they are published or not. The documents may come from teaching and research institutions in France or abroad, or from public or private research centers.
L'archive ouverte pluridisciplinaire HAL, est destinée au dépôt et à la diffusion de documents scientifiques de niveau recherche, publiés ou non, émanant des établissements d'enseignement et de recherche français ou étrangers, des laboratoires publics ou privés. 


\title{
Experimental study of the viscoelastic properties of green poplar wood during maturation
}

\author{
Guillaume Pot $\cdot$ Evelyne Toussaint • \\ Catherine Coutand · Jean-Benoît Le Cam
}

\begin{abstract}
During the radial growth of trees, internal stresses are created because of wood-cell maturation. Biomechanical models can compute these stresses, but they are currently limited by a lack of knowledge about the viscoelastic behavior of green wood. The aim of the present paper is to study the viscoelastic behavior of green wood and to obtain measurements of viscoelastic parameters. In order to accomplish this, the effect of internal maturation stresses on the studied samples was first eliminated by studying viscoelastic phenomena. Creep tests were then performed on small slats of wood using a cantilever bending test. It is shown that green wood viscoelastic behavior can be modeled with Burgers' model. The corresponding parameters are estimated with respect to the
\end{abstract}

G. Pot $(\bowtie) \cdot$ E. Toussaint

Institut Pascal, CNRS, UMR 6602, 63171 Aubière, France

e-mail: guillaume.pot@univ-bpclermont.fr

E. Toussaint

e-mail: evelyne.toussaint@univ-bpclermont.fr

G. Pot $\cdot$ E. Toussaint

Institut Pascal, Clermont Université, Université Blaise Pascal, BP 10448, 63000 Clermont-Ferrand, France

C. Coutand

UMR 547 PIAF, INRA 234 Avenue du Brézet,

63100 Clermont-Ferrand, France

e-mail: Catherine.coutand@clermont.inra.fr

C. Coutand

Clermont Université, Université Blaise Pascal, UMR 547 PIAF, 63000 Clermont-Ferrand, France

J.-B. Le Cam

LARMAUR, Université de Rennes 1, Bât. 10B, Campus de

Beaulieu, 35042 Rennes, France

e-mail: jean-benoit.lecam@univ-rennes1.fr wood-cells age. No significant difference between tension wood and normal wood is revealed, but it appears that green wood tends to lose its viscoelastic behavior with maturation.

\section{Introduction}

Trees control their posture by maintaining and modifying the orientation of their trunk and branches. In plant parts that have achieved their elongation, these gravitropic movements are ensured thanks to the asymmetrical differentiation of reaction wood. Reaction wood is produced on one side of the trunk or branch [1]. It is submitted to higher longitudinal stresses than "normal" wood, thus the difference in stresses between the two sides of the axis enables tree's movements. These stresses are mainly due to the wood-cell maturation process [2]. Wood cells are created by mother cells (called initials) of the cambium zone, which is located at the periphery of the trunk, between the wood and the bark. During their maturation, wood cells tend to shrink in the longitudinal direction, but these maturation strains are impeded by the cells created earlier, which are already stiffer, thus producing internal maturation stresses.

In most deciduous species, reaction wood is called tension wood (TW) because it is submitted to high longitudinal tension within the living tree [3]. Wood located on the other side of the axis is called opposite wood (OW). The high internal stresses caused by TW can cause damages during wood exploitation and processing. Thus, it is of interest to determine the internal stresses in the living tree to avoid or predict these damages.

Several models which enable the internal maturation stresses to be determined can be found in the literature. 
Kubler [4] was the first author to calculate the internal maturation stresses in the case of a symmetrically growing trunk for an elastic and transversally isotropic material. Archer and Byrnes [5] then extended these formulae for asymmetrical growth. Later, Fournier et al. [2] developed a semi-analytical model which showed that maturation stresses are much greater than stresses due to the selfweight of the tree. More recent biomechanical models have shown that viscoelasticity can increase the righting-up efficiency of trees [6, 7]. Nevertheless, none of these studies drew on experimental data for the viscoelastic properties used. Hence, it is necessary to evaluate these properties experimentally to determine quantitatively the effect of the viscoelasticity behavior of wood on the gravitropic process.

In the literature, most of the studies that deal with wood viscoelastic properties focus on mechano-sorptive behavior $[8,9]$. Indeed, in the living tree, wood contains a large amount of water, and the cells moisture content is above the fiber saturation point (which is about $30 \%$ moisture content) [10]. The physical properties of wood, in particular the mechanical properties, change significantly below the fiber saturation point [11]. In the context of modeling tree gravitropism, the viscoelastic properties of green wood, i.e., wood above the fiber saturation point, are necessary.

Viscoelastic studies focusing on green wood are very rare. Placet et al. [12] studied viscoelastic properties of watersaturated wood across the grain at different temperatures using harmonic tests. Dlouhá et al. [13] investigated the viscoelastic properties of tropical green wood along fibers through creep tests in the temperature range of $30-70{ }^{\circ} \mathrm{C}$. They showed a time-temperature equivalency. McLean et al. [14] performed tensile dynamic mechanical analysis on green and air-dried TW of tropical species at a frequency of $1 \mathrm{~Hz}$. Bremaud et al. [15] also performed dynamic mechanical analysis on wood of conifer trees and discussed the role of microfibril angle and lignin in vibrational properties. Finally, static creep tests were performed by Kojima and Yamamoto [16, 17]. They studied green wood with different cellulose microfibril angles and moisture contents. They used a simple Poynting-Thomson model to model the viscoelastic behavior of their samples. The measured relaxation time for green wood was between 20 and $80 \mathrm{~h}$.

To the best of the authors knowledge, no study deals with TW creep behavior, or the effect of maturation on viscoelastic properties. The aim of the present work is to characterize the viscoelastic properties of green poplar wood to enhance the prediction of biomechanical models of the gravitropic process. The effect of the maturation process on viscoelasticity is also discussed. The technique used was to study the creep behavior of wood samples obtained from trees which had been artificially inclined.
The creep test consists of measuring the time-dependent strain resulting from the application of a constant stress. However, wood in trees contains internal maturation stresses. Applying an external load to a sample thus increases the level of stresses. Internal maturation stresses can relax and modify the apparent behavior of the sample. In order to uncouple these two effects, it is necessary to first study the effect of internal maturation stresses on the time-dependent behavior of wood samples and to eliminate them. Then a classic creep test with constant stress can be performed. "Materials and methods" section describes the materials and methods used to perform these two steps. The results are presented and discussed in "Results and discussion" section.

\section{Materials and methods}

\section{Trees}

Seven two-year-old hybrid poplars (Populus deltoides $\times$ Populus nigra, cv I4551) planted in individual $60 \mathrm{~L}$ containers were studied. The trees were approximately $3 \mathrm{~m}$ high at the beginning of the experiment. They were inclined by tilting the pot by about $35^{\circ}$ from the vertical on 30th May 2011 at the beginning of the 3rd year's growth, according to the procedure described in [18]. The trees righted-up by producing TW on the upper side of the tilted axis (see cross-section in Fig. 1a). In most cases, the top of the trees reached a vertical position in less than two months. Trunk diameter was measured weekly with a caliper, allowing a diameter growth rate to be calculated. In the basal part of the trees (lower than $20 \mathrm{~cm}$ from ground), the mean diameter growth rate was $G=0.16 \pm$ $0.03 \mathrm{~mm} \mathrm{day}^{-1}$. One tree was felled approximately each week from 16th June to 8th August. Thus, a felling time after tilting can be defined.

\section{Wood sample preparation}

A piece of the trunk of $8 \mathrm{~cm}$ in length was taken from the basal part of each felled tree. It was chosen to avoid knots. Thus, the height from the ground at which the samples were taken was not the same from one tree to another, varying from 0 to $14 \mathrm{~cm}$.

From the $8 \mathrm{~cm}$-long segments, a board of $6 \mathrm{~mm}$ in width in the tangential direction was cut using a band saw in such a way that the saw cuts were parallel to the diameter running from the upper side to the lower side of the inclined tree (see Fig. 1a). Sawing along the pith, the lower side, containing OW, was separated from upper side, containing TW induced by artificial tilting. Next, the same experimental treatment was performed on the two sides: first, the 


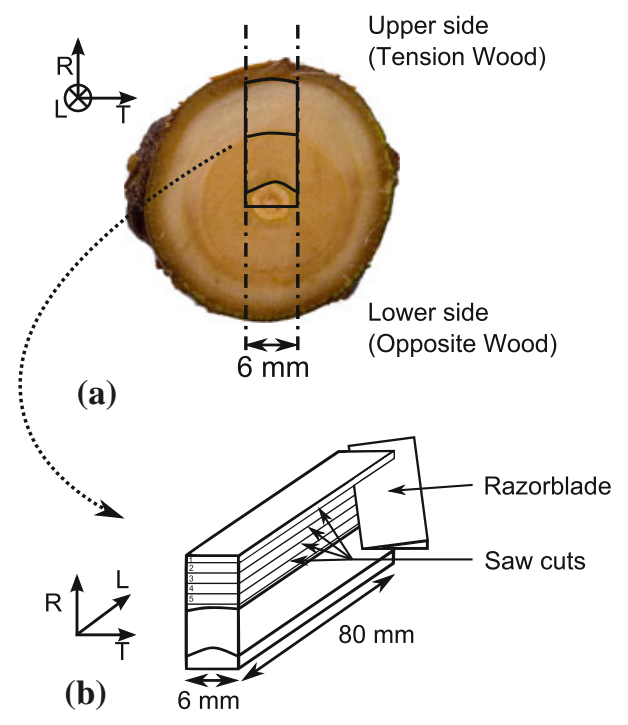

Fig. 1 Preparation of the samples. a Image of a cross-section of the trunk from which a board was cut along the diameter running from the upper side to the lower side of the inclined tree; $\mathbf{b}$ drawing of the half board from which small slats of $1.3 \mathrm{~mm}$ in thickness were cut with a razor blade

bark was manually removed; then approximately $1.3 \mathrm{~mm}$ thick slats were cut using a razorblade. These slats were the samples directly used for curvature measurements and creep tests. The samples were finally $80 \mathrm{~mm}$ in the longitudinal direction by $6 \mathrm{~mm}$ in the tangential direction, with a thickness of $1.3 \pm 0.2 \mathrm{~mm}$ in the radial direction (this mean value was measured for all the slats using a micrometer).

Several cuts were performed within each board from the cambium (i.e., outer side of the tree) to the previous growth ring (Fig. 1b). Contrary to saw cutting, cutting with a razorblade induced no loss of material. By this means that the complete sequence of slats represents the final intra-ring radial variation of the wood. The slats were set in water in plastic containers once they were cut in order to keep wood above the fiber saturation point. They were left at room temperature (about $20^{\circ} \mathrm{C}$ ).

Since the trees were cut at different periods of the season, the size of the last growth ring increased, and consequently the quantity of slats in this growth ring was different from one tree to another. Table 1 gives the quantity of slats cut from each side of each tree. The designation of the slats comprised the name of the tree, the type of wood (OW or TW) and the number of the slat, with number 1 for the first slat cut from the outer side of the trunk, and ascending sequentially as the slat became closer to the previous ring (for instance T24ow2 is the second slat cut from the lower side (i.e., OW) of the tree felled 24 days after tilting).
Table 1 Table of trees studied

\begin{tabular}{lll}
\hline $\begin{array}{l}\text { Tree name }(\mathrm{T}+ \\
\text { quantity of felling time } \\
\text { after tilting in days) }\end{array}$ & $\begin{array}{l}\text { Quantity of slats on } \\
\text { upper side }(\mathrm{TW})\end{array}$ & $\begin{array}{l}\text { Quantity of slats on } \\
\text { lower side }(\mathrm{OW})\end{array}$ \\
\hline T17 & 3 & 2 \\
T24 & 3 & 2 \\
T31 & 3 & 2 \\
T38 & 3 & 2 \\
T49 & 5 & 2 \\
T63 & 6 & 3 \\
T70 & 6 & 3 \\
\hline
\end{tabular}

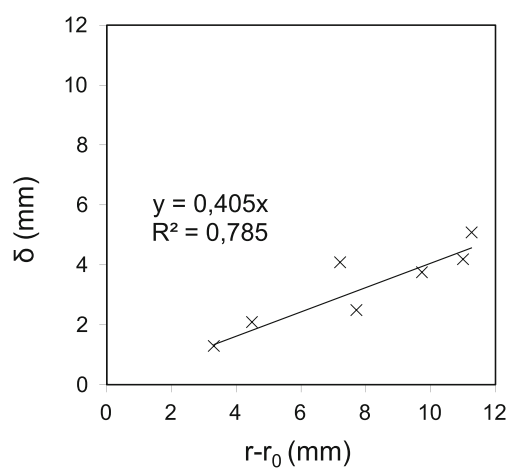

Fig. 2 Eccentricity versus growth for different trees

Determination of wood-cell age

Under the assumption of a constant growth rate on both sides of the trunk, it was possible to ascertain the wood-cell age of each slat by knowing the eccentricity of the trunk and the radial position of each slat. The eccentricity $\delta$ is the distance between the center of the circle representing the last growth ring and the center of the circle representing the previous rings (Fig. 1a). Eccentricity measurements are presented for the different trees in Fig. 2 according to growth, that is the difference between the radius of the tree $r$ at a given time and the radius $r_{0}$ at the beginning of the growing season.

Since there was a significant linear relationship between $\delta$ and $r-r_{0}$, an eccentricity coefficient $K_{\delta}$ was defined. Thus, we have the following equation:

$\delta=\left(r-r_{0}\right) K_{\delta}$

As shown in Fig. 2, $K_{\delta}$ was equal to 0.4. In this study, this value was assumed to be constant throughout the season. Coefficient $K_{\delta}$ allows the asymmetrical growth of the tree to be easily taken into account. In fact, the upper side and lower side growth rates (named respectively $G_{\mathrm{tw}}$ and $G_{\mathrm{ow}}$ ) were computed due to the eccentricity coefficient and diameter growth rate using the following equations: 
$G_{\mathrm{tw}}=\frac{G}{2}\left(1+K_{\delta}\right)$

$G_{\mathrm{ow}}=\frac{G}{2}\left(1-K_{\delta}\right)$

Growth rates were obtained due to the experimental values which were about $G_{\mathrm{tw}}=0.12 \mathrm{~mm} \mathrm{day}^{-1}$ and $G_{\mathrm{ow}}=$ $0.050 \mathrm{~mm} \mathrm{day}^{-1}$. With these growth rates, the mean age of the wood cells contained in a given slat was ascertained due to the radial position of this slat. Finally, this method enables properties to be represented according to the woodcells age, therefore to different maturation times.

\section{Autonomous curvature measurements}

Internal maturation stresses present in living trees can be released by sawing operations. The largest values of internal maturation stresses are found in the longitudinal direction [2]; thus, we can conjecture that potential deformation due to internal maturation stress relaxation can occur in this direction. Moreover, within the thickness of each slat, the maturation of wood cells induces a gradient in its physical properties. Finally, a curvature in the longitudinal-radial plane can occur.

High definition images $(3648 \times 2736$ pixels $)$ of the samples were first recorded immediately after cutting. The samples were placed on their side in the longitudinal-radial plane (Fig. 3). Further images were then regularly taken over a period of 8 weeks. The slats were maintained hydrated at about $20{ }^{\circ} \mathrm{C}$. The autonomous curvature of some samples increased with time (Fig. 3). Their curvature radius was calculated due to the images: the coordinates of about 40 reference points were measured along each sample using ImageJ software [19]. The data were then fitted by a circle using the least squares method with a MATLAB [20] routine. Curvature was defined as positive when the center of curvature was on the side toward the center of the trunk, and defined as negative otherwise. The coefficient of correlation was above 0.95 for all the samples. Finally, a curvature radius was attributed to each image of each sample during the slats autonomous deformation.

\section{Creep tests}

Creep tests were performed on the same samples as those used for autonomous curvature measurements. Assuming that when the autonomous curvature of the samples reached a maximum the internal maturation stresses were fully relaxed, no effect due to internal maturation stresses could interfere with the bending creep tests. In order to keep the wood cells saturated with water, the experiments were performed in a water-filled aquarium. A simple test

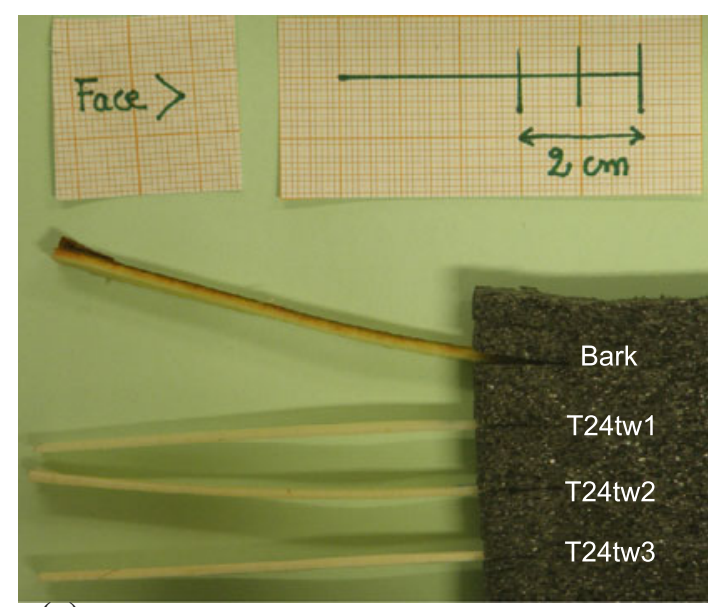

(a)

June 232011

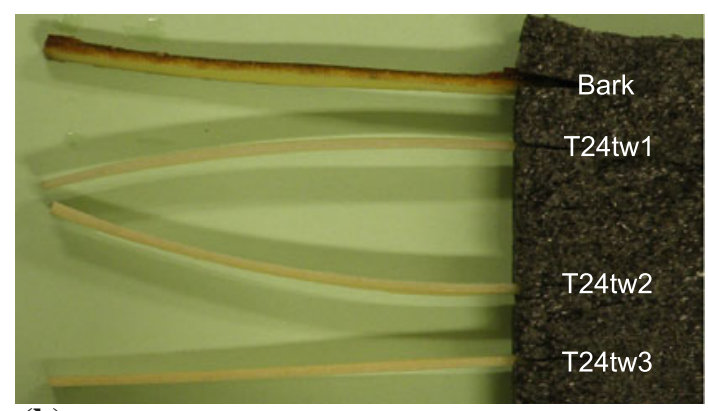

(b)

Fig. 3 Pictures of the same TW samples of tree T24 in the longitudinal-radial plane: a $5 \mathrm{~min}$ after cutting, b 1 week after cutting

bench designed to hold several samples was submerged in the aquarium. The samples were anchored at one end by clamping them over a length of $22 \mathrm{~mm}$ between two aluminum plates maintained by a screw. Weights were suspended from the free end of the samples; thus a constant load was applied. Within the hypothesis of small displacements [21], flexural moment and stress were assumed to be constant over time. The samples were thus subjected to creep. Using this test-bench, wood is tested in bending similarly to a cantilever beam. Moreover, all the samples of one tree can be tested at the same time. The samples of tree T49 were tested just after the autonomous curvature measurements from October 4, 2011 to November 28, 2011. The samples of tree T63 were tested from December 5, 2011 to January 10, 2012. No more samples were tested, since they may have been affected by the storage period.

The deflection of the samples was measured without any contact thanks to image analysis. A scale was also submerged in the aquarium in the same plane as the samples. Two vertical reference points were chosen on this scale; they were compared over time to the position of the load application point. Images were regularly acquired over a period of 6 weeks. Deflection was calculated as the vertical 
difference between unloaded and loaded state. Due to the high-definition images $(3648 \times 2736$ pixels $)$, the minimum displacement that could be measured (i.e. the spatial resolution) was about $0.1 \mathrm{~mm}$.

Within the same tree, samples at different radial positions are at different maturation states. Thus, they have different stiffnesses. Applied creep loads had to be different to obtain a similar deflection for each sample. Preliminary 3-point bending tests were performed on samples cut from the same tree, but at different heights [22]. A modulus of elasticity depending on radial position was obtained. Thus, it was possible to evaluate a modulus of elasticity thanks to these results, and finally to calculate the load necessary to obtain a given initial deflection value for any sample depending on its radial position in the tree.

A theoretical initial deflection of $3 \mathrm{~mm}$ was chosen. Elasticity modulus, applied load and measured initial deflection are presented in Table 2 for each sample. Note that three samples ruptured when the load was applied. This could be explained by an inappropriate tightening of the anchored end of these samples. After initial loading, deflection was measured with time for all the samples (Table 2). Some samples presented a high-initial deflection (T49ow2, T49tw2, T49tw4). Peculiar attention was paid to the results obtained for these samples, since they can be misevaluated under the small displacement hypothesis. However, as a first approximation, compliance $J(t)$ was calculated with the following equation:

$J(t)=\frac{3 I v(t)}{P L^{3}}$

Table 2 Table of samples used for creep test and loads appliedto obtain a deflection close to $3 \mathrm{~mm}$

\begin{tabular}{llcl}
\hline $\begin{array}{l}\text { Sample } \\
\text { name }\end{array}$ & $\begin{array}{l}\text { Modulus of elasticity } \\
(\mathrm{MPa})\end{array}$ & $\begin{array}{l}\text { Applied load } \\
(\mathrm{mN})\end{array}$ & $\begin{array}{l}\text { Initial deflection } \\
(\mathrm{mm})\end{array}$ \\
\hline T49ow1 & 1661 & 20 & 3.3 \\
T49ow2 & 3217 & 111 & 7.9 \\
T49tw1 & 1525 & 20 & 1.8 \\
T49tw2 & 5810 & 348 & 6.0 \\
T49tw3 & 6128 & 373 & Broken \\
T49tw4 & 3849 & 273 & 5.5 \\
T49tw5 & 2824 & 152 & 4.5 \\
T63ow1 & 2151 & 70 & 2.5 \\
T63ow2 & 2002 & 73 & 2.9 \\
T63ow3 & 2972 & 71 & 2.7 \\
T63tw1 & 2152 & 72 & Broken \\
T63tw2 & 4323 & 154 & 2.7 \\
T63tw3 & 6507 & 273 & 0.6 \\
T63tw4 & 4956 & 111 & Broken \\
T63tw5 & 2122 & 83 & 1.8 \\
T63tw6 & 3231 & 152 & 2.9 \\
\hline
\end{tabular}

In this equation, $I$ is the second moment of area, $v(t)$ is the deflection which depends on time, $P$ is the applied load, and $L$ is the free sample length (measured for each sample; the mean value was $54 \pm 1 \mathrm{~mm}$ ).

A rheological model that models wood viscoelastic behavior is proposed later in this paper. The experimental results of $J(t)$ were fitted numerically to this rheological model due to the curve fitting toolbox of MATLAB with the mean square method to obtain the viscoelastic parameters.

\section{Results and discussion}

Behavior of small slats under internal maturation stresses

Figure 4 shows the representative temporal evolution of the autonomous curvature of samples cut from the same tree and subjected to their internal maturation stresses. Initial curvature is closed to zero. Autonomous curvature increases significantly in absolute value for TW samples close to the cambium (see for example samples T24tw1 and T24tw2; Fig. 3). Neither the other TW samples in the inner part of the ring nor the OW samples display curvature.

The explanation of this autonomous curvature principally comes from the fact that the samples are subjected to a gradient of internal maturation stresses from the external side to the internal side of the slat. This stress gradient produces a bending moment which induces an autonomous curvature if the samples are thin enough to flex. Since green wood is a viscoelastic material, the curvature changes with time as creep occurs. At the same time, the stresses progressively relax.

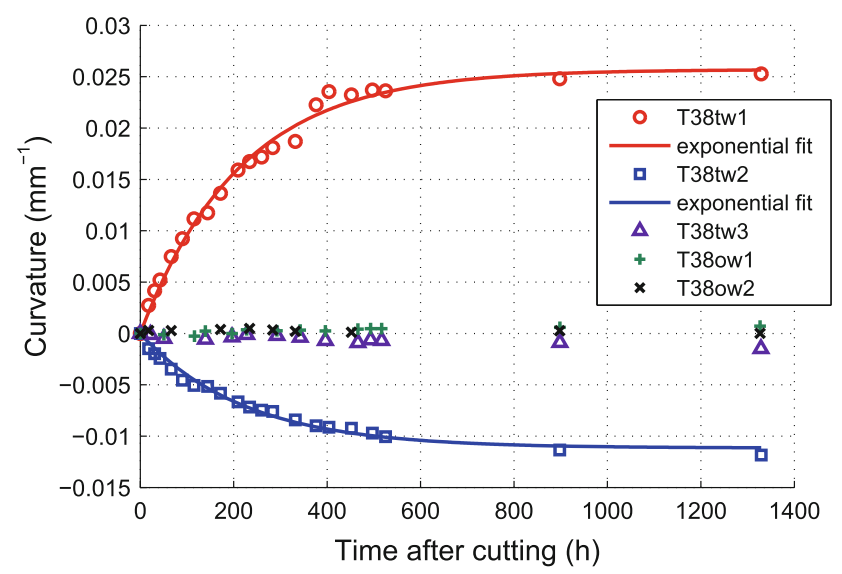

Fig. 4 Typical results in terms of the temporal evolution of samples' autonomous curvature (tree T38) 



Fig. 5 Characteristic parameters of autonomous curvature temporal evolution for samples of the different trees studied with respect to the time of felling after inclining. Vertical segments represent a $95 \%$ curve fitting confidence interval. tw 1 is the first slat cut from the outer side of the trunk, tw2 the second one in the direction of the pith

The experimental data from curving samples was fitted with the following exponential function:

$\chi(t)=\chi_{\infty}\left(1-\mathrm{e}^{-t / \tau}\right)$

In this equation, $\chi$ is the curvature, $t$ is the time, $\chi_{\infty}$ is the asymptote of the curve, and $\tau$ is a characteristic time. Therefore, each sample can be characterized by two constants, $\chi_{\infty}$ and $\tau$. They are represented with respect to felling time after inclining in Fig. 5 for the first and second samples close to the cambium.

Figure 5a shows that the first TW sample close to the periphery of the trunk presents a positive curvature in the axis system chosen, while the second TW sample presents a negative curvature. This shows that the sign of the gradient of internal maturation stresses is different between these samples. In the literature, tree internal maturation stresses are calculated under the assumption of the instantaneous maturation and elastic behavior of wood [2, $4,5]$. The result is an internal maturation stress logarithmic curve that exhibits a radial gradient of stresses in the trunk. It is represented by a dashed line in Fig. 6. Since it is monotonous, this stress profile cannot explain the different autonomous curvature directions between the first and second TW samples. In reality, if we consider that cells close to the cambium are not totally mature, then there is a positive stress gradient while the cells are maturating. Furthermore, the maturation of peripheral cells induces a compression of the inner cells; the stress gradient therefore becomes negative for these inner cells (similarly to the instantaneous maturation models in the literature). Figure 6 shows such a supposed stress profile. This stress profile can explain the difference in sign for the autonomous curvature of the slats. In a previous study [23], it was showed that infradensity increases until a distance of about $1.5 \mathrm{~mm}$ from the cambium; thus the cells are not fully matured until at least this distance, which corresponds to the thickness of the samples used in this study. This is consistent with the explanation proposed here to interpret the different directions of autonomous curvature.

The third and fourth slats of all the trees do not curve over time, whereas the gradient of stress should be significant, according to elastic models $[2,4,5]$. This discrepancy can be explained by relaxation phenomena which decrease the gradient of stress for more mature wood. Thus, the radial stress gradient is too low to produce curvature, as shown in Fig. 6. Moreover, OW samples also do not curve. This can be explained by lower stresses and/or a

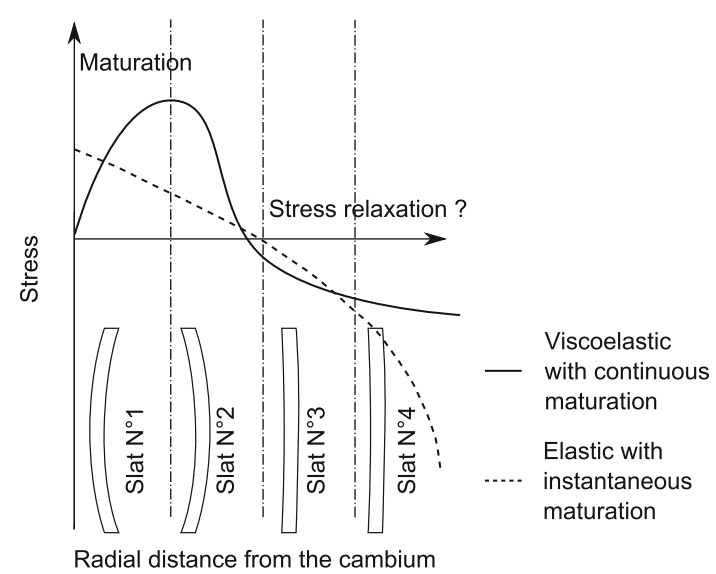

Fig. 6 Diagram of probable internal maturation stress profile on TW side assuming wood as a viscoelastic material with continuous maturation (solid line), compared to one calculated under the assumption of wood as an elastic material with instantaneous maturation (dashed line according to Kubler [4]). Vertical dashdotted lines represent the separation between the different slats according to radial distance from the cambium. These slats and their autonomous curvatures are depicted below the curves 
slat thickness that is too high to correspond to a high gradient of stress due to lower radial growth on this side.

Quantitatively, the asymptote of autonomous curvature is lower in absolute value for the second samples than for the first ones (Fig. 5a): the mean value of $\chi_{\infty}$ was respectively -0.009 and $0.019 \mathrm{~mm}^{-1}$. This can be explained either by the lower stiffness of these slats or by lower internal maturation stresses. No significant correlation with felling time appears. In terms of the characteristic time $\tau$ (Fig. 5b), no clear difference appears between the first and second TW samples. The mean value of $\tau$ is $240 \mathrm{~h}$. At this stage of the study it is difficult to interpret these results, because both creep and relaxation can occur (the samples curve by themselves and stresses relax).

\section{Creep tests results}

Since the autonomous curvature of the samples has reached its asymptote, internal maturation stresses are supposed to be fully relaxed when the slats are used for creep tests. Therefore the samples experience only stresses due to the external load, and only creep occurs, since the stress is constant (within the small displacement hypothesis).

Creep curves for the studied samples are presented in Fig. 7a, b. Both TW and OW creep curves first present an exponential part, then reach an oblique asymptote. This behavior can be modeled by Burgers' model (Fig. 8). The creep function of this model is given by the following function:

$J(t)=\frac{1}{E_{0}}+\frac{t}{\eta_{\infty}}+\frac{1}{E_{1}}\left(1-\mathrm{e}^{-t / \tau_{1}}\right)$

The parameters of this equation are the same as in Fig. 8: $E_{0}$ is the elastic modulus, $\eta_{\infty}$ is the linear viscosity of the dashpot in series, $E_{1}$ is the spring modulus in parallel and $\tau_{1}=\left(\eta_{1} / E_{1}\right)$ is the relaxation time.

Such a model is rarely used in the literature. Fridley et al. [24] noted that it is sometimes used for dry wood. Actually, Burgers' model was used by Haque et al. [25], then Moutee et al. [26] to study wood deformation while drying. However, to our best knowledge green wood has never been modeled using Burgers' model. This can be explained by the singularity of our work, which studies green wood creep over a longer period than usually. Generally in the literature creep tests last about $300 \mathrm{~h}$, as in [16], and these tests are not performed on wood in different maturation stages. This can explain why the oblique asymptote that typically occurs when a material behaves as in Burgers' model has never been noticed for green wood.

A numerical fit of the curves in Fig. 7 enables us to obtain the four viscoelastic parameters of Burgers model. They are plotted with respect to wood-cell age in Fig. 9. Under the assumption of a constant maturation process in
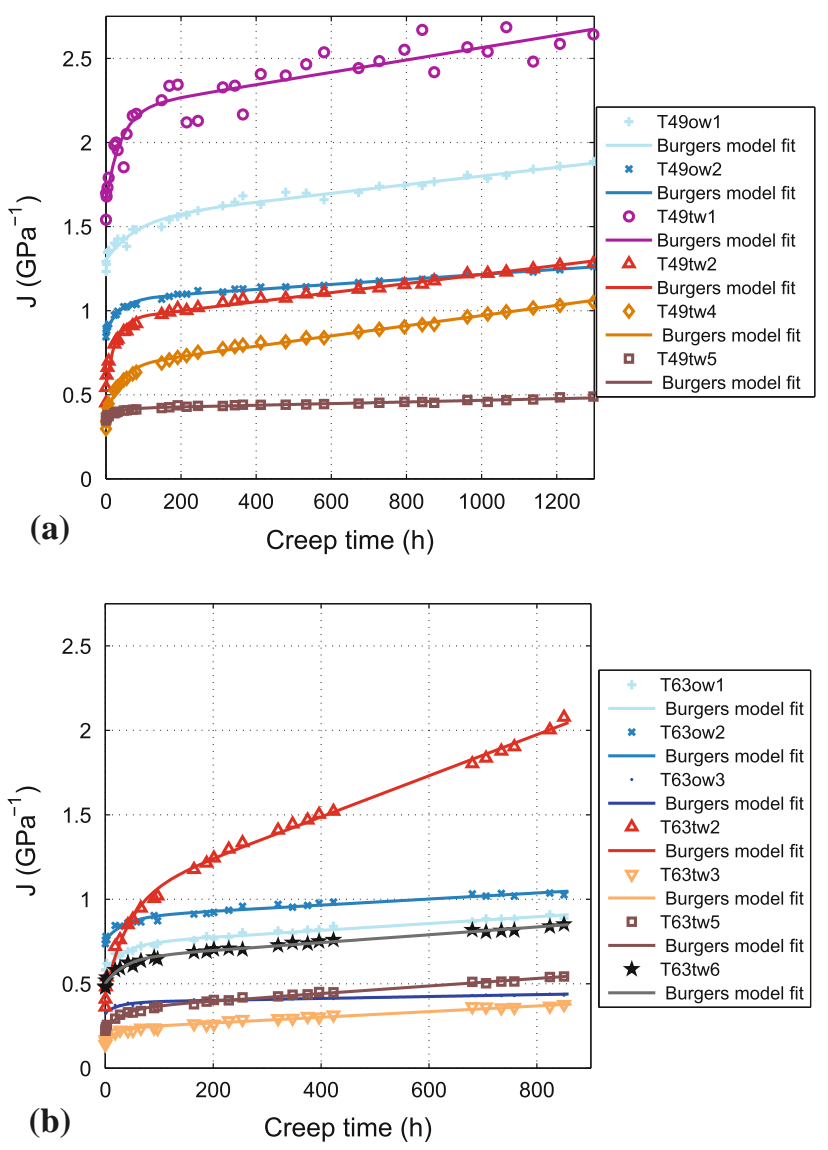

Fig. 7 Compliance according to creep time for samples of Table 2 (no results for broken samples). a Tree T49, b Tree T63

terms of viscoelastic properties during the vegetative season, these results correspond to the evolution of the viscoelastic properties of green poplar wood according to maturation time. Note that samples which exhibit highinitial deflection do not present abnormal values. Thus, the small displacement hypothesis seems to be sufficient as regards the accuracy of this study.

The elastic modulus $E_{0}$ (Fig. 9a) is between 1 and 7 $\mathrm{GPa}$, which is consistent with the measurements revealed by a bending test in a previous study [22] (these moduli are presented in Table 2). $E_{0}$ mainly increases with wood-cell age for OW samples, but no clear evolution for TW samples appears. However, the measurement of the elastic modulus was not the objective of this study, and it can be measured by other means [22, 23].

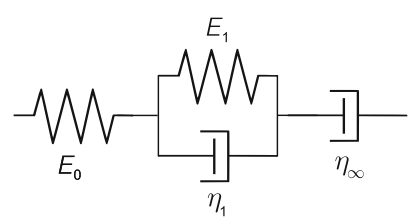

Fig. 8 Representation of Burgers' rheological model that fits the curves of Fig. 7 

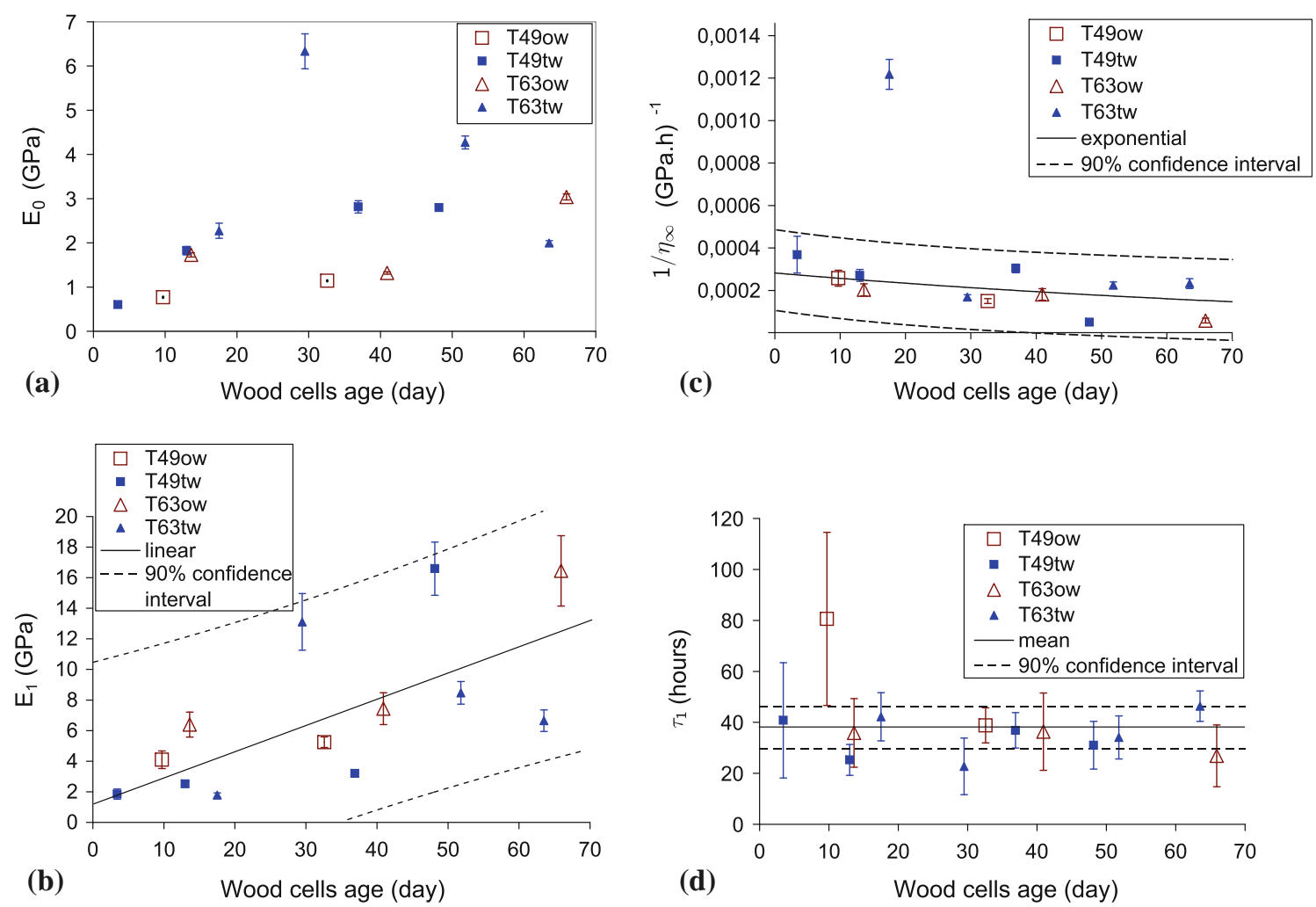

Fig. 9 Burgers' model parameters versus wood-cell age for two different trees and both OW and TW. The error bars represent a $95 \%$ confidence interval for the fit of $J(t)$ curves. Note that for some results the error bar is not visible because it is smaller than the size of the marker

Except for $E_{0}$, the variations in viscoelastic parameters with respect to wood-cell age appear very similar between OW and TW samples. This would seem to show that viscoelastic behavior does not depend on the type of wood considered. The slope of the oblique asymptote, $1 / \eta_{\infty}$ tends to decrease with wood-cell age (see Fig. 9b). Conversely, $E_{1}$ increases with wood-cell age (see Fig. 9c). Higher $E_{1}$ and lower $1 / \eta_{\infty}$ for more mature wood show that wood tends to lose its viscoelastic behavior with maturation. Moreover, $\tau_{1}$ does not show any variation according to wood-cell age (see Fig. 9d). The mean value of $\tau_{1}$ was $38 \pm 8 \mathrm{~h}$.

These results present quite a high variability, which can be attributed to the wood itself. They cannot be compared to any data in the literature since no study dealing with green poplar wood viscoelasticity exists. Despite their variability, these results allow us to obtain reasonable values for the viscoelastic parameters of green poplar wood.

\section{Conclusion}

In this study, the viscoelastic behavior of small slats of green poplar wood is considered when samples are subjected to their own internal maturation stresses. With a slat thickness of about $1.3 \mathrm{~mm}$ in the radial direction, only the first two TW samples in the outer part of the trunk curve with time. Neither the other TW samples in the inner part of the ring nor OW samples curve. These results can be explained by internal maturation stress relaxation.

Creep tests were performed when the autonomous curvature of the samples had stopped and thus their stresses were fully relaxed. The experimental setup was designed to keep the wood saturated in water and to measure the creep of the samples without contact. The evolution of the creep of each sample was fitted by Burgers' rheological model. Burgers' model parameters were studied according to the mean wood-cells' age of each sample, which is determined by the radial position, radial growth rate, and eccentricity. No significant difference appears between TW and OW viscoelastic properties. However, green wood shows a tendency to lose its viscoelastic behavior with maturation.

The results of this experimental study provide information on the viscoelasticity of green wood, which can be useful for other works dealing with green wood. In particular, the viscoelastic parameters obtained can be used in a biomechanical model such as the Coutand et al. model [7] to check quantitatively the effect of viscoelasticity on gravitropic reaction. 
Acknowledgements This work was supported by a Grant from the Auvergne Regional Council and the European Regional Development Fund.

\section{References}

1. Scurfield G (1973) Science 179:647

2. Fournier M, Chanson B, Thibaut B, Guitard D (1991) Ann For Sci 48:527

3. Sinnott EW (1952) Am J Bot 39:69

4. Kubler H (1959) Holz Roh Werkstoff 17:1

5. Archer RR, Byrnes FE (1974) Wood Sci Technol 8:184

6. Dlouha J, Alméras T, Clair B et al. (2008) Acta Univ Agric Silv Mendel Brun 56:39

7. Coutand C, Mathias J-D, Jeronimidis G, Destrebecq J-F (2011) J Theor Biol 273:115

8. Wang JZ, Dillard DA, Kamke FA (1991) J Mater Sci 26:5113. doi:10.1007/BF01143201

9. Ebrahimzadeh PR, Kubát DG (1993) J Mater Sci 28:5668. doi: 10.1007/BF00367845

10. Bowyer JL, Shmulsky R, Haygreen JG (2007) Forest products and wood science: an introduction, 5th revised edn. Iowa State University Press, Ames

11. Bach L (1966) Abstract of thesis in Forest Products Journal, vol $16, \mathrm{p} 53$
12. Placet V, Passard J, Perré P (2008) J Mater Sci 43:3210. doi: 10.1007/s10853-008-2546-9

13. Dlouhá J, Clair B, Arnould O et al. (2009) Holzforschung 63:327

14. McLean JP, Arnould O, Beauchene J, Clair B (2012) Ann For Sci 69:399

15. Bremaud I, Ruelle J, Thibaut A, Thibaut B (2013) Holzforschung $67: 75$

16. Kojima Y, Yamamoto H (2004) J Wood Sci 50:301

17. Kojima Y, Yamamoto H (2005) J Wood Sci 51:462

18. Coutand C, Fournier M, Moulia B (2007) Plant Physiol 144:1166

19. Abramoff MD, Magalhães PJ, Ram SJ (2004) Biophotonics Int $11: 36$

20. Gilat A (2004) MATLAB: an introduction with applications, 2nd edn. New York: Wiley

21. Timoshenko S (1953) History of strength of materials. McGrawHill, New York

22. Pot G (2012) Thesis of Blaise Pascal University

23. Pot G, Coutand C, Le Cam J-B, Toussaint E (2013) Wood Sci Technol 47:7

24. Fridley KJ, Tang RC, Soltis LA (1992) J Struct Eng 118:2261

25. Haque MN, Langrish TG, Keep LB, Keey RB (2000) Wood Sci Technol 34:447

26. Moutee M, Fafard M, Fortin Y, Laghdir A (2005) Wood Fiber Sci 37:521 